

\title{
Localized intermolecular electronic coupling in two-dimensional self-assembled $3,4,9,10$-perylenetetracarboxylic diimide nanoarchitectures
}

Jérémy Hieulle, Fabien Silly

\section{To cite this version:}

Jérémy Hieulle, Fabien Silly. Localized intermolecular electronic coupling in two-dimensional selfassembled 3,4,9,10-perylenetetracarboxylic diimide nanoarchitectures. Journal of Materials Chemistry C, 2013, 1 (30), pp.4536-4539. 10.1039/c3tc30771a . cea-01481322

HAL Id: cea-01481322

https://hal-cea.archives-ouvertes.fr/cea-01481322

Submitted on 2 Mar 2017

HAL is a multi-disciplinary open access archive for the deposit and dissemination of scientific research documents, whether they are published or not. The documents may come from teaching and research institutions in France or abroad, or from public or private research centers.
L'archive ouverte pluridisciplinaire HAL, est destinée au dépôt et à la diffusion de documents scientifiques de niveau recherche, publiés ou non, émanant des établissements d'enseignement et de recherche français ou étrangers, des laboratoires publics ou privés. 


\section{Journal of \\ Materials Chemistry C}

RSCPublishing

\section{Localized intermolecular electronic coupling in two-dimensional self-assembled 3,4,9,10- \\ perylenetetracarboxylic diimide nanoarchitectures}

Cite this: J. Mater. Chem. C, 2013, 1, 4536
Received 24th April 2013

Accepted 24th May 2013

DOI: $10.1039 / c 3 t c 30771 a$

www.rsc.org/MaterialsC

\author{
Jérémy Hieulle and Fabien Silly*
}

Tailoring the structural and electronic properties of perylene diimide derivative films is essential for developing next generation organic photovoltaic devices. Here we show that 3,4,9,10-perylenetetracarboxylic diimide (PTCDI) molecules self-assemble into a new two-dimensional structure after annealing. Scanning tunneling microscopy (STM) reveals strong localized inter-molecular electronic coupling at room temperature when molecules are arranged in a side-by-side packing.
Perylene diimide derivatives are fascinating molecular building blocks for developing organic devices due to their outstanding chemical and thermal stability as well as their long-lasting photostability. ${ }^{\mathbf{1}}$ Intense research effort is focused on functionalizing a perylene diimide skeleton to optimize or to tune the packing and electronic properties of this molecular building block. ${ }^{\mathbf{1 - 1 0}}$ Perylene derivatives sublimated under vacuum have the ability to self-assemble on flat metal surfaces and to form two-dimensional hydrogen-bonded nanoarchitectures. ${ }^{\mathbf{1 1 - 1 7}}$ These molecules can also form multicomponent organic structures when mixed with complementary building blocks. ${ }^{18-22}$ Perylene derivatives are thus very attractive to fabricate new devices as new organic flat-heterojunction solar cells for example. Annealing is often used to reduce disorder in organic films and to improve the performance of devices based on organic building blocks. ${ }^{23,24}$ Improvement of charge carrier mobility is often attributed to a higher degree of order in the solid state, but molecular organization can also be a key parameter. For example molecular cofacial orientation is expected to promote vertical electronic coupling through $\pi-\pi$ molecular interactions. This cofacial packing is presumed to enhance electronic communication between neighboring molecules in a column-type stacking, enabling efficient charge transport, ${ }^{25,26}$ through the molecular skeleton. However little is known about how the electronic properties of organic layers can be locally affected by lateral intermolecular electronic coupling.

Here we investigate the structure and electronic properties of 3,4,9,10-perylenetetracarboxylic diimide (PTCDI) self-assembled nanoarchitectures on $\mathrm{Au}(111)$. Scanning tunneling microscopy (STM) in ultra high vacuum reveals structuredependent lateral intermolecular electronic coupling in a PTCDI layer after annealing.

CEA, IRAMIS, SPCSI, Hybrid Magnetic Nanoarchitectures, F-91191 Gif sur Yvette, France. E-mail: fabien.silly@cea.fr; Fax:+33(0)169088446; Tel: +33(0)169088019
Experiments were performed in an ultrahigh vacuum (UHV) chamber at a pressure of $10^{-8} \mathrm{~Pa}$. The $\mathrm{Au}(111)$ surfaces were sputtered with $\mathrm{Ar}^{+}$ions and then annealed in UHV at $600{ }^{\circ} \mathrm{C}$ for $1 \mathrm{~h}$. PTCDI molecules, Fig. 1a, were evaporated at $250{ }^{\circ} \mathrm{C}$ and then deposited on the gold surface kept at room temperature. Cut Pt/Ir tips were used to obtain constant current STM images at room temperature with a bias voltage applied to the sample. STM images were processed and analyzed using the home made FabViewer application. $^{27}$

Fig. 1b shows the $\mathrm{Au}(111)$ surface after deposition of PTCDI molecules at room temperature. Self-assembled PTCDI domains are observed using STM. These domains are entirely covering the $\mathrm{Au}(111)$ surface at high concentration. Molecules are forming chains running parallel to each other. Molecules from neighboring chains are tilted in the opposite direction by the same angle of $\pm 12^{\circ}$. Analysis of the STM image shows that PTCDI chains are stabilized by double-hydrogen bonds $(\mathrm{N}-\mathrm{H} \cdots$ O) between imide groups of adjacent molecules, as it is confirmed by density functional theory calculations. ${ }^{15}$ The model of this structure is presented in Fig. 1c. The network unit cell of this 'canted' structure is a parallelogram with $\sim 1.6 \mathrm{~nm}$ and $\sim 1.5 \mathrm{~nm}$ unit cell constants and an angle of $\sim 95^{\circ}$ between the axes.

Fig. 1d shows the PTCDI network on $\mathrm{Au}(111)$ after $2 \mathrm{~h}$ postannealing at $50{ }^{\circ} \mathrm{C}$. Molecules are now forming a new twodimensional nanoarchitecture that has not been predicted by previous calculations. ${ }^{15}$ The model of this structure is presented in Fig. 1e. The network unit cell is a parallelogram with $\sim 2.4 \mathrm{~nm}$ and $\sim 1.4 \mathrm{~nm}$ unit cell constants and an angle of $\sim 105^{\circ}$ between the axes. Molecules are forming double-PTCDI chains separated by a single-PTCDI chain. PTCDI chains are stabilized by the double-hydrogen bonds between imide groups previously observed in Fig. 1b. The PTCDI double-chains are composed of two close-packed PTCDI chains, i.e. the molecules of neighboring chains are packed side-by-side. The molecules of each 
a
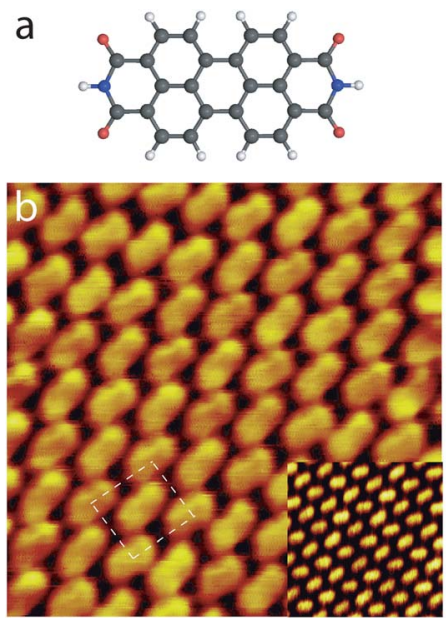

C
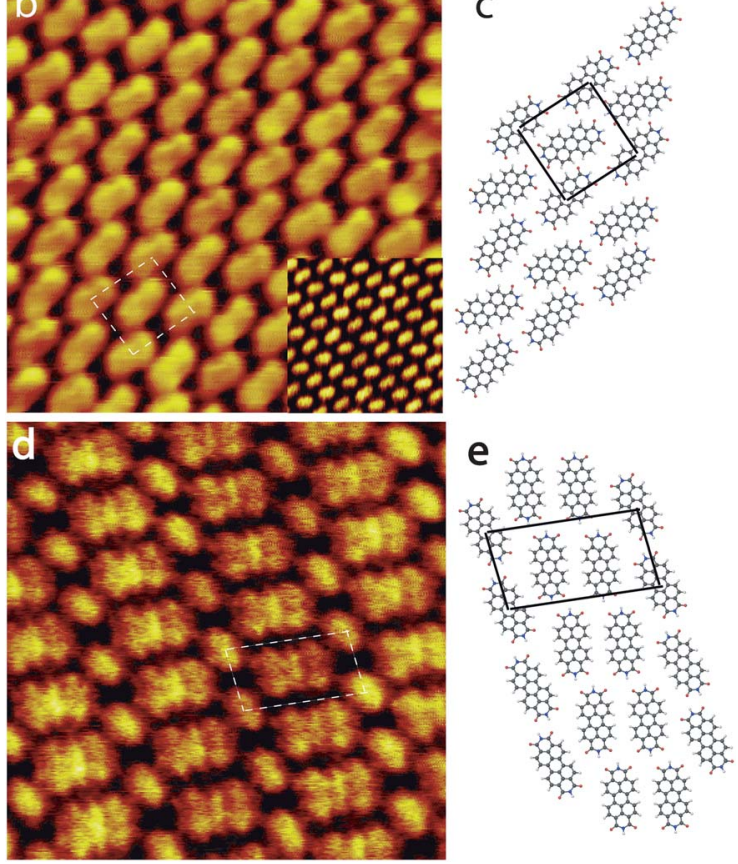

Fig. 1 (a) Schematic of a PTCDI molecule. Blue, red, light gray and white balls correspond to nitrogen, oxygen, carbon and hydrogen atoms, respectively. (b) STM images of the PTCDI network on $\mathrm{Au}(111)$ at room temperature; $7 \times 7 \mathrm{~nm}^{2}, V_{\mathrm{s}}=-0.5$ $V_{1} I_{t}=0.8 \mathrm{nA}$. Inset: $7 \times 7 \mathrm{~nm}^{2} ; V_{s}=-0.811 V_{1} I_{t}=0.211 \mathrm{nA}$. (c) Model of the PTCDI canted network. (d) STM images of the PTCDI network on $\mathrm{Au}(111)$ after $50{ }^{\circ} \mathrm{C}$ annealing; $7 \times 7 \mathrm{~nm}^{2}, V_{\mathrm{s}}=-0.811 \mathrm{~V}, l_{\mathrm{t}}=0.211 \mathrm{nA}$. (e) Model of the PTCDI doublechain nanoarchitecture. The PTCDI network unit cells are represented by white dotted lines in the STM images on the left and by black lines in the models on the right.

chain have the same orientation, i.e. molecules are rotated by an angle of $+12^{\circ}$ in comparison with the chain direction. The molecules of the single-chain separating PTCDI double-chains are rotated in the opposite direction by an angle of $-12^{\circ}$.

Fig. 2 reveals that the contrast of the PTCDI double-chains in the STM images is strongly affected by tunneling parameters. For a tunneling bias of $-0.811 \mathrm{~V}$, the gap between two neighboring PTCDI molecules in the PTCDI double-row appears bright, Fig. 2a. For a tunneling bias of $-0.411 \mathrm{~V}$, the contrast of all PTCDI molecules is similar, Fig. 2b. In contrast the gap between two neighboring PTCDI molecules in the PTCDI double-chain structure appears darker for a tunneling bias of $-0.211 \mathrm{~V}$, Fig. 2c. In addition the darkest area in the STM image is located in the center of the double-chain, in the gap separating two paired-molecular building blocks, Fig. 2c. It should be noticed that the PTCDI molecules of the single-chains appear slightly brighter than the molecules of the double-chains, Fig. 2c. To that extent molecular contrast in the STM image at $-0.811 \mathrm{~V}$ is reversed in comparison to the STM features observed at $-0.211 \mathrm{~V}$.

PTCDI molecules can also locally form a triple-chain structure on $\mathrm{Au}(111)$ upon annealing, Fig. 3a and b. The PTCDI triple-chain is composed of three side-by-side close-packed PTCDI chains. For a tunneling bias of $-0.111 \mathrm{~V}$, the gap between side-by-side PTCDI molecules of neighboring chains appears bright in the triple-chain structure, Fig. 3a. In comparison, for a tunneling bias of $-0.211 \mathrm{~V}$ the molecules of the central chain appear brighter, Fig. 3c. The cross section shown in Fig. $3 \mathrm{~d}$ reveals that the height of the PTCDI molecules

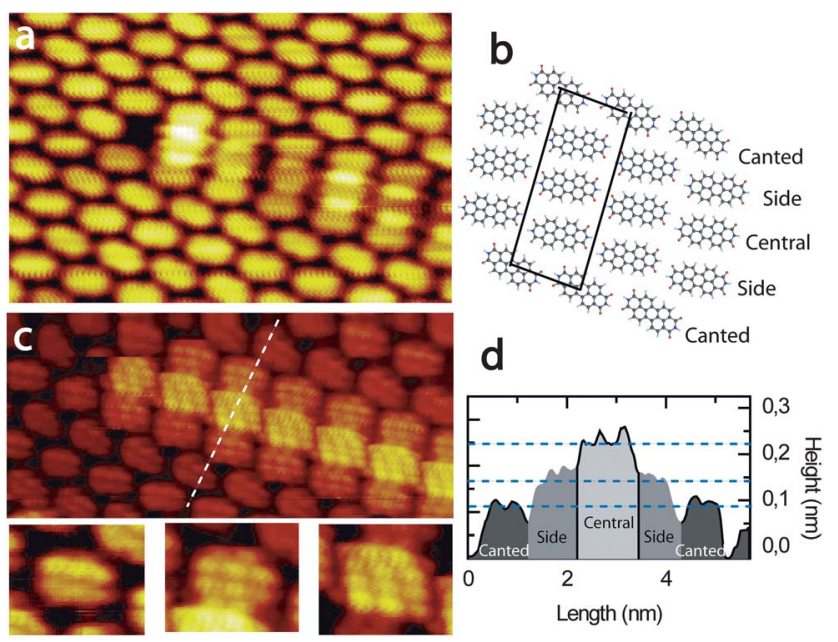

Fig. 3 STM image of the PTCDI triple-chain structure on Au(111), (a) $10 \times 7 \mathrm{~nm}^{2}$, $V_{s}=-0.111 \mathrm{~V}, I_{t}=411 \mathrm{pA}$ (model of the triple-chain PTCDI structure in (b)); (c) $12 \times$ $5 \mathrm{~nm}^{2}, V_{\mathrm{s}}=-0.211 \mathrm{~V}, l_{\mathrm{t}}=411 \mathrm{pA}$. Inset: canted PTCDI molecule (left), side-chain molecule (center) and central-chain molecule (right), $3 \times 2 \mathrm{~nm}^{2}$. (d) Profile taken along the dotted line in (c). The profile of the canted PTCDI molecule is represented in dark gray, the profile of the side-chain PTCDI molecule is represented in gray and the profile of the central-chain PTCDI molecule is represented in light gray.
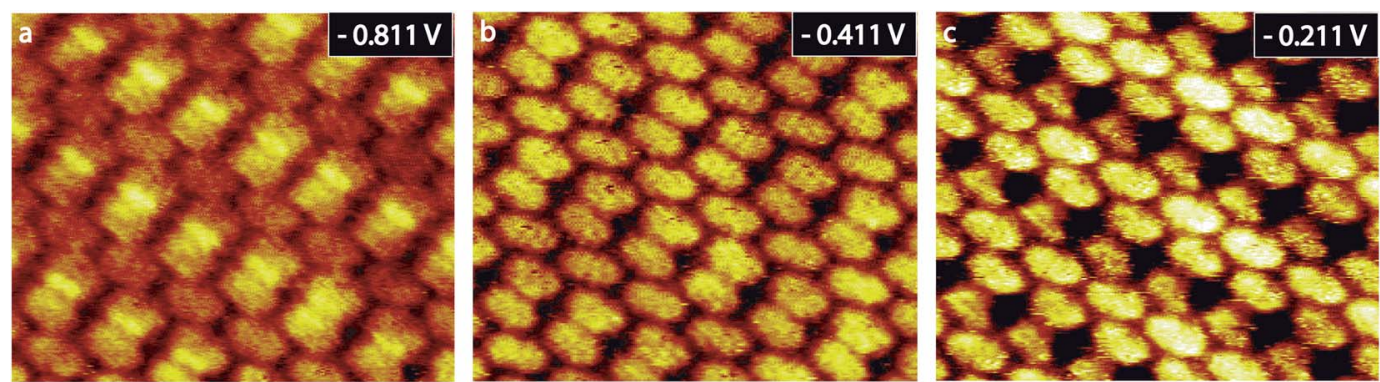

Fig. 2 Influence of tunneling parameters on the contrast in STM images of the PTCDI network on Au(111). The STM images in (a), (b), (c) have been recorded successively using the tunneling parameters: (a) $V_{\mathrm{s}}=-0.811 \mathrm{~V}, I_{\mathrm{t}}=311 \mathrm{pA}$, (b) $V_{\mathrm{s}}=-0.411 \mathrm{~V}, I_{\mathrm{t}}=311 \mathrm{pA}$, (c) $V_{\mathrm{s}}=-0.211 \mathrm{~V}, I_{\mathrm{t}}=311 \mathrm{pA}$, respectively. Image size: $7 \times 7 \mathrm{~nm}{ }^{2}$. 
in the side-chain of the triple-chain structure appears $\sim 0.5 \AA$ smaller than the PTCDI height in the central chain and appears $\sim 0.5 \AA$ higher than the PTCDI height in the canted structure. In addition intramolecular features are visible on the high resolution STM image in Fig. 3c. Molecules of the central-chain are composed of twelve bright spots. In contrast molecules of the side-chain are composed of ten bright spots, and molecules of the canted PTCDI structure are composed of two bright stripes.

STM images demonstrate that the electronic properties of the PTCDI film are strongly modified by the organic layer structure. Tunneling parameters are drastically affecting molecular contrast in the STM images when molecules are arranged in a side-by-side arrangement in the double and triple chain structures. STM especially shows that new electronic states appear in the gap separating side-by-side molecules at $-0.811 \mathrm{~V}$ (Fig. 1d and 2a), i.e. new electronic states induced by lateral inter-molecular coupling are created by the side-by-side molecular arrangement. Surprisingly these electronic states are also delocalized onto the whole molecular skeleton at specific tunneling parameters. The contrast of the molecules in the double and triple-chain thus differs from the contrast of the molecules in the canted structure (Fig. 2c and 3c). For example the molecules of the central chain in the triple-chain structure appear the brightest at $-0.211 \mathrm{~V}$, followed by the molecules of the side rows. In comparison the molecules of the canted structure are the darkest, Fig. 3c. In addition STM images also show that intramolecular features are strongly affected by molecular location in the triple-chain structure. Particularly the number and the position of bright spots constituting the molecule in the STM image are different for the molecules located in the central and in the side chains of the triple chain structure, Fig. 3c. It therefore appears that the thermally activated side-by-side molecular packing drastically affects the electronic properties of the whole molecular skeleton. Interestingly molecules having only one side-by-side neighbor have a symmetrical shape in the STM images; i.e. the molecules are composed of two parallel rows of three bright spots and two external rows of two bright spots at $-0.211 \mathrm{~V}$, Fig. 3c. In comparison molecules having two side-by-side neighbors have a parallelogram shape in the STM images. These molecules are composed of four rows of three bright spots. These rows are slightly shifted in comparison to each other leading to a molecular parallelogram shape despite PTCDI having a rectangular-like skeleton, Fig. 1a. This shows that intermolecular binding affects molecular electronic properties so strongly that the molecular integrated density of states recorded in the STM images differs from molecular geometric shape.

The STM measurements therefore reveal that charge transport across the perylene derivative layer would not only depend on the electronic properties of individual organic building blocks but also could be greatly enhanced or reduced by the structure of the organic layer. The side-by-side molecular arrangement is opening new electronic channels through the PTCDI layer. Electron transport from the gold surface to the STM tip is favored at $-0.811 \mathrm{~V}$ in the gap between side-by-side molecules in the double-row structure. This channel disappears at $-0.411 \mathrm{~V}$. At a voltage of $-0.211 \mathrm{~V}$, electron transport from the surface to the STM tip is locally reduced; side-by-side molecules appear darker in the double chain structure. The position of these electronic channels is shifted in energy in the triple-chain structure. For example the favored electronic channel localized in the gap between side-by-side molecules appears at $-0.111 \mathrm{~V}$ in the triple-chain structure whereas it appears at $-0.811 \mathrm{~V}$ in the double-chain structure. These observations are of prime importance in the field of organic photovoltaic for example, where perylene derivatives are widely used as building blocks. This opens new possibilities for improving charge transport in organic devices. In order to understand the appearance of these new electronic states induced by the side-by-side packing of the molecules on $\mathrm{Au}(111)$, one would have to compare high resolution scanning tunneling spectroscopy spectra ${ }^{28}$ or synchrotron valence band spectra $^{29}$ with a local density of states calculation for these monolayers adsorbed on the gold surface. Since these structures are incommensurable and the PTCDI monolayer unit cells are quite large, this kind of calculation would be difficult to achieve at present.

In summary we investigated temperature-dependent PTCDI two-dimensional self-assembly on $\mathrm{Au}(111)$ in ultra high vacuum using scanning tunneling microscopy. STM images show that molecules self-assemble into a hydrogen-bonded canted structure at room temperature. After $50{ }^{\circ} \mathrm{C}$ post-annealing, PTCDI molecules self-assemble into new double and triple-chain structures. STM images recorded at different bias reveal strong electronic coupling between molecules packed side-by-side. This electronic coupling strongly affects molecular contrast and molecular shape in the STM images. These observations show that post-annealing can be used not only to modify the structure of the perylene-based film as it is usually expected but also to create new electronic states. This is of huge interest to engineer new perylene diimide-based nanoarchitectures having specific electronic properties for organic devices.

\section{Acknowledgements}

The research leading to these results has received funding from the European Research Council under the European Union's Seventh Framework Programme (FP7/2007-2013)/ERC grant agreement no. 259297. The authors also acknowledge financial support from Triangle de la Physique and Cnano Région Ile de France. The authors would like to thank Christophe Lubin, Frédéric Merlet and Sylvain Foucquart for precious technical support.

\section{References}

1 C. Li and H. Wonneberger, Adv. Mater., 2012, 24, 613636.

2 H. Yang, A. J. Mayne, G. Comtet, G. Dujardin, Y. Kuk, P. Sonnet, L. Stauffer, S. Nagarajan and A. Gourdon, Phys. Chem. Chem. Phys., 2013, 15, 4939-4946.

3 M. Yu, W. Xu, N. Kalashnyk, Y. Benjalal, S. Nagarajan, F. Masini, E. Laegsgaard, M. Hliwa, X. Bouju, A. Gourdon, C. Joachim, F. Besenbacher and T. R. Linderoth, Nano Res., 2012, 5, 903-916. 
4 A. Herrmann and K. Müllen, Chem. Lett., 2006, 35, 978-985. 5 Y. Avlasevich, C. Li and K. Müllen, J. Mater. Chem., 2010, 20, 3814-3826.

6 S. Yagai, M. Usui, T. Seki, H. Murayama, Y. Kikkawa, S. Uemura, T. Karatsu, A. Kitamura, A. Asano and S. Seki, J. Am. Chem. Soc., 2012, 134, 7983-7994.

7 I. Willerich and F. Gröhn, J. Am. Chem. Soc., 2011, 133, 20341-20356.

8 N. Tasios, C. Grigoriadis, M. R. Hansen, H. Wonneberger, C. Li, H. W. Spiess, K. Müllen and G. Floudas, J. Am. Chem. Soc., 2010, 132, 7478-7487.

9 C.-C. You and F. Würthner, J. Am. Chem. Soc., 2003, 125, 9716-9725.

10 J. van Herrikhuyzen, A. Syamakumari, A. P. H. J. Schenning and E. W. Meijer, J. Am. Chem. Soc., 2004, 126, 1002110027.

11 Q. H. Wang and M. C. Hersam, Nat. Chem., 2009, 1, 206-211.

12 H. Huang, S. Chen, X. Gao, W. Chen and A. T. S. Wee, ACS Nano, 2009, 3, 3431-3436.

13 M. Mura, X. Sun, F. Silly, H. T. Jonkman, G. A. D. Briggs, M. R. Castell and L. N. Kantorovich, Phys. Rev. B: Condens. Matter Mater. Phys., 2010, 81, 195412.

14 C. Weiss, C. Wagner, R. Temirov and F. S. Tautz, J. Am. Chem. Soc., 2010, 132, 11864-11865.

15 M. Mura, F. Silly, G. A. D. Briggs, M. R. Castell and L. N. Kantorovich, J. Phys. Chem. C, 2009, 113, 21840-21848.

16 R. Temirov, S. Soubatch, O. Neucheva, A. C. Lassise and F. S. Tautz, New J. Phys., 2008, 10, 053012.
17 J. Lobo-Checa, M. Matena, K. Muller, J. H. Dil, F. Meier, L. H. Gade, T. A. Jung and M. Stohr, Science, 2009, 325, 300-303.

18 R. Madueno, M. T. Räisänen, C. Silien and M. Buck, Nature, 2008, 454, 618-621.

19 M. E. Canas-Ventura, K. Aït-Mansour, P. Ruffieux, R. Rieger, K. Müllen, H. Brune and R. Fasel, ACS Nano, 2011, 5, 457-469.

20 C. Silien, M. T. Räisänen and M. Buck, Small, 2010, 6, 391394.

21 X. Sun, M. Mura, H. T. Jonkman, L. N. Kantorovich and F. Silly, J. Phys. Chem. C, 2012, 116, 2493-2499.

22 X. Sun, H. T. Jonkman and F. Silly, Nanotechnology, 2010, 21, 165602.

23 P. E. Keivanidis, I. A. Howard and R. H. Friend, Adv. Funct. Mater., 2008, 18, 3189-3202.

24 J. P. Schmidtke, R. H. Friend, M. Kastler and K. Müllen, J. Chem. Phys., 2006, 124, 174704.

25 J. E. Bullock, R. Carmieli, S. M. Mickley, J. Vura-Weis and M. R. Wasielewski, J. Am. Chem. Soc., 2009, 131, 1191911929.

26 M. J. Ahrens, L. E. Sinks, B. Rybtchinski, W. Liu, B. A. Jones, J. M. Giaimo, A. V. Gusev, A. J. Goshe, D. M. Tiede and M. R. Wasielewski, J. Am. Chem. Soc., 2004, 126, 8284-8294. 27 F. Silly, J. Microsc., 2009, 236, 211-218.

28 X. Lu, M. Grobis, K. H. Khoo, S. G. Louie and M. F. Crommie, Phys. Rev. Lett., 2003, 90, 096802.

29 D. R. T. Zahn, G. N. Gavrila and G. Salvan, Chem. Rev., 2007, 107, 1161-1232. 